\title{
Inhibition of Endotoxin-induced Bacterial Translocation in Mice
}

\author{
Edwin A. Deitch," Li Ma," Wen J. Ma, " Matthew B. Grisham, ${ }^{\ddagger}$ D. Neil Granger, ${ }^{\ddagger}$ Robert D. Specian, and Rodney D. Berg" \\ Departments of *Surgery, ${ }^{\ddagger}$ Physiology, $\$$ Anatomy, and "Microbiology, Louisiana State University Medical Center, \\ Shreveport, Louisiana 71130
}

\begin{abstract}
The primary functions of the gut are to absorb nutrients and exclude bacteria and their products. However, under certain circumstances the gut may lose its barrier function and serve as a reservoir for systemic microbial infections. These experiments were performed to determine the mechanisms whereby endotoxin causes bacteria to escape (translocate) from the gut. Bacteria translocated from the gut to the mesenteric lymph nodes of mice challenged with nonlethal doses of Escherichia coli 026:B6 or $E$. coli 0111:B4 endotoxin. Physical disruption of the gut mucosal barrier appears to be the primary mechanism whereby endotoxin promotes bacterial translocation. Mucosal injury and endotoxin-induced bacterial translocation were reduced by inhibition (allopurinol) or inactivation (tungsten diet) of xanthine oxidase activity $(P<0.01)$, but were not affected by the platelet-activation factor antagonists, SRI 63-441 or BN 52021. Because the inhibition or inactivation of xanthine oxidase activity reduced both the extent of mucosal injury and endotoxin-induced bacterial translocation, the effect of endotoxin on the gut appears to be mediated, at least to some degree, by xanthine oxidase-generated, oxygen-free radicals.
\end{abstract}

\section{Introduction}

The intestinal mucosa, in addition to its role in nutrient absorption, functions as a major barrier that prevents bacteria colonizing the gut from invading systemic organs and tissues. Based on epidemiologic studies, the mucosal barrier to bacteria appears to be lost under certain clinical circumstances, resulting in systemic sepsis, and in some instances this loss of barrier function may lead to the development of the multiple organ failure syndrome $(1,2)$. We have demonstrated that bacteria normally contained within the gut lumen can cross the mucosal barrier and survive in the mesenteric lymph node and other systemic organs, a process termed bacterial translocation (3). Factors that promote bacterial translocation from the gut include disruption of the indigenous gastrointestinal (GI) microflora leading to bacterial overgrowth, impaired host immune defenses, and physical disruption of the gut mucosal barrier (4).

Address reprint requests to Dr. Edwin A. Deitch, Department of Surgery, Louisiana State University Medical Center, P.O. Box 33932, Shreveport, LA73110.

Received for publication 29 June 1988 and in revised form 24 February 1989.

J. Clin. Invest.

(C) The American Society for Clinical Investigation, Inc. 0021-9738/89/07/0036/07 \$2.00

Volume 84, July 1989, 36-42
Endotoxin increases gut permeability, alters host immune defenses, and is relatively common in patients at increased risk of developing infections with enteric microorganisms (5). Consequently, we investigated whether nonlethal doses of endotoxin would promote bacterial translocation (5). Endotoxin (Escherichia coli 026:B6) administered either intramuscularly or intraperitoneally promotes bacterial translocation in a dose-dependent fashion (5). The magnitude of endotoxin-induced bacterial translocation is similar between CD-1 and $\mathrm{C} 3 \mathrm{H} / \mathrm{HeJ}$ (endotoxin hyporesponsive) mice, indicating that genetic resistance to the systemic effects of endotoxin is not associated with resistance to endotoxin-mediated bacterial translocation. The combination of endotoxin injection plus either a nonlethal thermal injury or a protein-malnourished state resulted in the development of lethal systemic infections originating from the gut $(6,7)$. The purpose of this work was to investigate the effects of endotoxin on the gut mucosal barrier to bacteria.

\section{Methods}

Animals. Specific pathogen-free (SPF) CD-1 mice were purchased from Charles River Breeding Laboratories, Wilmington, MA and used to establish a breeding colony. The SPF mice were housed under barrier-sustained conditions in autoclaved polystyrene cages (Maryland Plastics, New York, NY) with stainless steel lids covered with individual filter tops (Econo-filter, Scientific Products, Grand Prairie, TX). The mice were maintained with Purina Laboratory. Chow (Ralston Purina Co., St. Louis, MO) and acidified water $(0.001 \mathrm{~N} \mathrm{HCl})$ was given ad lib. Ground corn cob bedding was used in the cages (San-ICel; Paxton Processing Co., Inc., Paxton, IL). 8-wk-old animals of both sexes were used in these experiments. The animals were maintained in accordance with the recommendations of the Guidelines for the Care and Use of Laboratory Animals and the experiments were approved by the Louisiana State University Medical Center Shreveport Animal Care Committee.

Bacterial translocation. Mice were killed by cervical dislocation and the abdomen was soaked with $70 \%$ alcohol. The skin and peritoneum were opened with sterile scissors. The exposed viscera were swabbed with a sterile, cotton-tipped applicator stick that was placed in a tube containing $5.0 \mathrm{ml}$ of brain-heart infusion (BHI) ${ }^{1}$ to detect bacterial contamination. To determine translocation to the mesenteric lymph node (MLN), the MLN was excised, weighed, and placed in 0.5 $\mathrm{ml}$ of BHI, then homogenized with glass-reinforced teflon grinders (Tri-R Instruments; Rockville Center, NY). 0.2-ml aliquots of the homogenate were plated on blood agar and MacConkey's agar. The plates were incubated at $37^{\circ} \mathrm{C}$ for $24 \mathrm{~h} .3 \mathrm{ml}$ of $\mathrm{BHI}$ was added to the remaining $0.1 \mathrm{ml}$ of the MLN homogenate and incubated overnight at $37^{\circ} \mathrm{C}$. Any growth was subcultured for identification. The gram-negative, enteric bacilli were identified with the API 20E system (Analtab Products, Plainview, NY). Theoretically, even one viable bacterium in the MLN will be detected using these culturing procedures.

1. Abbreviations used in this paper: BHI, brain-heart infusion; GI, gastrointestinal; MLN, mesenteric lymph node; SPF, specific pathogen free. 
After the MLN was excised, the cecum was removed aseptically, weighed, and placed in BHI. The ceca were homogenized with teflon grinders and dilutions of the cecal homogenates were cultured on selective MacConkey's agar to determine the population levels of gramnegative, enteric bacilli and on nonselective blood agar to determine the population levels of total aerobic bacilli. Strict anaerobic bacteria were not quantitated.

Antibiotic decontamination. The mice received $4 \mathrm{mg}$ of streptomycin sulfate and $4 \mathrm{mg}$ of bacitracin per $\mathrm{ml}$ of drinking water for $4 \mathrm{~d}$ to eliminate the indigenous GI tract microflora as previously described (4). The antibiotic-decontaminated mice were orally inoculated with $E$. coli $\mathrm{C} 25$, a streptomycin-resistant strain of $E$. coli.

Morphologic analysis. The intestinal mucosa structure of the distal ileum was analyzed by light microscopy of semithin plastic sections. Samples of the distal ileum were immersed in Carson's modified Millonig's phosphate-buffered formalin solution (37-40\% formaldehyde solution $10 \mathrm{ml}$; tap water $90 \mathrm{ml}$; sodium phosphate monobasic $1.86 \mathrm{~g}$; sodium hydroxide $0.42 \mathrm{~g}$ ) for at least $6 \mathrm{~h}$. The tissues were dehydrated to $95 \%$ ethanol and embedded in glycol methacrylate (JB-4 Polyscience, Inc., Warrington, PA). The JB-4 sections $(2 \mu \mathrm{m})$ were stained with $1 \%$ toluidine blue in $1 \%$ sodium borate buffer and photographed with an Olympus Vanox microscope (Olympus Corporation of America, New Hyde Park, NY).

Experimental groups. A total of 336 animals were used in this study. Bacterial translocation was measured in 10 mice receiving saline only and in 62 mice receiving only $E$. coli 026:B6 endotoxin ( $2 \mathrm{mg}$ i.p.) (Sigma Chemical Co., St. Louis, MO). The effect of $E$. coli 0111:B4 endotoxin (List Biological Laboratories, Campbell, CA) on bacterial translocation or survival was tested over a range of doses (from 0.05 to $0.50 \mathrm{mg}$ ) in 78 mice.

Allopurinol (Sigma Chemical Co.), an inhibitor of xanthine oxidase, was suspended in methylcellulose $(2 \mathrm{mg} / \mathrm{ml})$ and administered orally by gastric lavage at a dose of $50 \mathrm{mg} / \mathrm{kg}$ to 32 mice, 48 and $24 \mathrm{~h}$ before receiving endotoxin or saline intraperitoneally. An additional eight mice that had been monoassociated with $E$. coli $\mathrm{C} 25$, received allopurinol orally $(50 \mathrm{mg} / \mathrm{kg}$ per d) for $2 \mathrm{~d}$ to determine whether allopurinol would reduce the translocation of $E$. coli $\mathrm{C} 25$. Eight control, $E$. coli $\mathrm{C} 25$-monoassociated mice received saline daily for $2 \mathrm{~d}$ before sacrifice. The effect of methycellulose $(0.7 \mathrm{ml})$ without allopurinol on endotoxin-induced bacterial translocation was tested in 10 mice.

28 mice were placed on a diet supplemented with sodium tungstate $(0.7 \mathrm{~g} / \mathrm{kg}$ ), but restricted in molybdenum (ICN Biochemical, Cleveland, $\mathrm{OH})$. This diet contains normal levels of protein and meets the National Research Council requirements for vitamins, minerals, and trace elements. To deplete intestinal levels of xanthine oxidase activity, the mice were maintained on this diet a minimum of $14 \mathrm{~d}$ before experimentation (8). Additionally, the mice were only allowed to drink glass-distilled deionized water, because molybdenum is present in undistilled tap water. To verify that intestinal xanthine oxidase activity was inactivated, the intestinal xanthine dehydrogenase and xanthine oxidase activities of control, endotoxin-treated, and tungstate diettreated mice were measured by the method of Waud and Rajagopolan (9), in which xanthine oxidase-dependent uric acid formation was assessed at $295 \mathrm{~nm}$.

To determine whether endotoxin-induced bacterial translocation was mediated by platelet-activating factor (PAF), two different specific PAF antagonists were tested. Either SRI 63-441 or BN 52021 (20 $\mathrm{mg} / \mathrm{kg}$ i.p.) was administered $\mathbf{3 0} \mathrm{min}$ before the endotoxin challenge (10). SRI 63-441 was a generous gift of Dr. L. Makowka (Univ. of Pittsburg). BN 52021 was a generous gift of Dr. P. Braquet (Institute of Henri Beaufour, France).

Polymyxin-B (Burroughs Wellcome Co., Research Triangle Park, NC) $(0.03 \mathrm{mg})$ was incubated with E. coli $026: \mathrm{B} 6(2.0 \mathrm{mg})$ or $0111: \mathrm{B} 4$ $(0.10 \mathrm{mg})$ endotoxin at $20^{\circ} \mathrm{C}$ for $3 \mathrm{~h}$. The polymxyin-B-endotoxin mixtures were then injected intraperitoneally into mice and bacterial translocation measured $24 \mathrm{~h}$ later. Control groups consisted of mice receiving endotoxin only or gentamicin (Schering Corp., Kenilworth,
NJ) $(0.03 \mathrm{mg})$ plus endotoxin mixtures. The doses of polymixin B or gentamicin used were below their therapeutic levels, so they would not inhibit bacterial growth.

Statistical analysis. Translocation indices (discontinuous data) were evaluated by chi-square analysis with the Yates correction factor. Continuous data were analyzed by the $t$ test or by analysis of variance (ANOVA). Data are expressed as mean \pm SEM unless otherwise specified. $P<0.05$ was considered significant.

\section{Results}

Bacteria translocated from the gut to the MLN in $80 \%$ of the mice administered $2 \mathrm{mg}$ i.p. of $E$. coli $026: \mathrm{B} 6$ endotoxin (Table I). These results are similar to those reported previously, in which nonlethal doses of this endotoxin preparation induced bacterial translocation to the MLN (5). To determine whether the endotoxin of other $E$. coli strains would promote bacterial translocation at nonlethal doses, $E$. coli 0111:B4 endotoxin was tested over a range of doses, from 0.05 to $0.50 \mathrm{mg}$. The administration of 0.50 or $0.25 \mathrm{mg}$ of $E$. coli 0111 :B4 endotoxin was associated with a $100 \%$ mortality rate within $48 \mathrm{~h}$ of administration. In contrast, only 1 of 10 mice died within $7 \mathrm{~d}$ of receiving $0.10 \mathrm{mg}$ of $E$. coli $0111: \mathrm{B} 4$ endotoxin and none of 10 mice died after receiving a $0.05-\mathrm{mg}$ injection. Therefore, bacterial translocation was tested in mice receiving these lower doses of endotoxin. Bacteria translocated to the MLN of $50 \%$ of mice challenged with $0.05 \mathrm{mg}$ and $69 \%$ of mice challenged with $0.10 \mathrm{mg}$ of $E$. coli 0111:B4 endotoxin (Table I). Thus,

Table I. Effect of Endotoxin on Bacterial Translocation with or without Inhibition or Inactivation of Xanthine Oxidase Activity

\begin{tabular}{|c|c|c|c|c|}
\hline \multirow[b]{2}{*}{ Group } & \multicolumn{3}{|c|}{ Translocation to $\mathrm{MLN}^{*}$} & \multirow{2}{*}{$\begin{array}{l}\text { Ileal xanthine } \\
\text { oxidase }^{*}\end{array}$} \\
\hline & $n$ & Incidence & CFU/MLN & \\
\hline & \multicolumn{3}{|c|}{$\%$} & $\begin{array}{c}\text { Activity } m U / \\
g \text { wet } w t\end{array}$ \\
\hline Control & 10 & 0 & 0 & $250 \pm 5^{\S}$ \\
\hline \multicolumn{5}{|c|}{ E. coli $026: \mathrm{B} 6$ endotoxin } \\
\hline$(2.0 \mathrm{mg})$ & 30 & 80 & $1,607 \pm 658$ & $427 \pm 75$ \\
\hline \multicolumn{5}{|c|}{ E. coli $0111: \mathrm{B} 4$ endotoxin } \\
\hline$(0.05 \mathrm{mg})$ & 10 & 50 & $1,660 \pm 464$ & ND \\
\hline \multicolumn{5}{|c|}{ E. coli 0111 :B4 endotoxin } \\
\hline$(0.10 \mathrm{mg})$ & 13 & 69 & $704 \pm 160$ & ND \\
\hline Allopurinol & 16 & 0 & 0 & ND \\
\hline \multicolumn{5}{|c|}{ Allopurinol plus endotoxin } \\
\hline$(026: B 6)$ & 16 & $31^{\prime \prime}$ & $220 \pm 113^{\S}$ & ND \\
\hline Tungsten diet & 10 & 0 & 0 & 0 \\
\hline \multicolumn{5}{|c|}{ Tungsten diet plus endotoxin } \\
\hline$(026: B 6)$ & 18 & $17^{\top}$ & $144 \pm 94^{\S}$ & $\mathbf{0}$ \\
\hline
\end{tabular}

* Incidence is expressed as percent of mice with viable bacteria cultured from their MLN; bacterial counts expressed as mean \pm SEM colony-forming units (CFU) of bacteria per gram of MLN in animals whose MLNs contained bacteria.

‡ To verify that intestinal xanthine oxidase was inactivated, intestinal xanthine dehydrogenase and xanthine oxidase activities were measured in control and tungsten diet-treated mice.

${ }^{\S} P \leq 0.05$ versus $E$. coli 026 :B6 or $E$. coli $0111: \mathrm{B} 4$ endotoxin $(0.10$ $m g)$.

" $P \leq 0.01$ versus $E$. coli $026: \mathrm{B} 6$ endotoxin and $P<0.05$ versus $E$. coli 0111 :B4 endotoxin $(0.10 \mathrm{mg})$.

' $P \leq 0.01$ versus $E$. coli 026 :B6 or $E$. coli 0111 :B4 endotoxin $(0.10$ $m g$ ). 
although the doses required to induce bacterial translocation were different between $E$. coli 0111:B4 endotoxin and $E$. coli 026:B6 endotoxin, both induced bacterial translocation when given at nonlethal doses.

Next, we investigated whether inhibition of xanthine oxidase activity by allopurinol or inactivation of xanthine oxidase activity by a sodium tungstate diet would prevent endotoxininduced bacterial translocation. The incidence and magnitude of endotoxin-induced bacterial translocation to the MLN were significantly reduced by either the inhibition or inactivation of xanthine oxidase activity (Table I). Methylcellulose alone without allopurinol did not stop endotoxin-induced bacterial translocation, because bacterial translocation occurred in $60 \%$ (6 of 10) of mice pretreated with methylcellulose for $48 \mathrm{~h}$ before endotoxin challenge. The ability of the tungstenenriched diet to reduce endotoxin-induced bacterial translocation appears to be due solely to the added tungsten, because endotoxin-induced bacterial translocation occurred in 7 of 10 mice fed an identical diet not containing tungsten. Neither allopurinol nor the tungsten diet blocked endotoxin-induced bacterial translocation by decreasing gut population levels of indigenous bacteria, because the levels of total gram-negative enterics were similar in all the groups receiving endotoxin (Table II).

Both allopurinol and the tungsten diet appeared to reduce bacterial translocation by preventing endotoxin-mediated gut injury of the distal ileum. As demonstrated by light microscopy, endotoxin caused villous edema, separation of the epithelium from the basal lamina, and produced gross breaks in the epithelial barrier in some areas (Fig. 1). None of these epithelial changes were evident in control tissues or in tissues from tungsten-fed or allopurinol-treated animals (Fig. 1).

To determine the specificity of these findings, we tested the effect of allopurinol on bacterial translocation in a model in which translocation is induced by intestinal bacterial overgrowth. In this model, bacterial translocation is not associated with activation of xanthine oxidase or with gut mucosal damage (4). Because allopurinol administration did not inhibit bacterial translocation in mice monoassociated with $E$. coli C25 (Table III), it appears that the reduction in endotoxin-in-

Table II. Effect of Endotoxin on Cecal Bacterial Population Levels with or without Inhibition or Inactivation of Xanthine Oxidase Activity

\begin{tabular}{lccc}
\hline \multicolumn{1}{c}{ Group } & $n$ & Gram-negative enterics* & Total aerobic \\
\hline $\begin{array}{l}\text { Control } \\
\text { E. coli 026:B6 }\end{array}$ & 10 & $1.0 \pm 0.8 \times 10^{6} \ddagger$ & $9.0 \pm 3.2 \times 10^{7} \ddagger$ \\
$\quad$ endotoxin & 30 & $6.6 \pm 2.8 \times 10^{7}$ & $15.4 \pm 4.2 \times 10^{8}$ \\
$\begin{array}{l}\text { Allopurinol } \\
\text { Allopurinol plus }\end{array}$ & 16 & $2.0 \pm 0.7 \times 10^{6}$ & $4.5 \pm 1.1 \times 10^{8}$ \\
$\quad$ endotoxin (026:B6) & 16 & $5.1 \pm 3.8 \times 10^{7}$ & $21.9 \pm 4.4 \times 10^{8}$ \\
$\begin{array}{l}\text { Tungsten diet } \\
\text { Tungsten diet plus } \\
\text { endotoxin (026:B6) }\end{array}$ & 10 & $\mathrm{ND}$ & $\mathrm{ND}$ \\
& 18 & $13.5 \pm 8.4 \times 10^{7}$ & $6.4 \pm 5.2 \times 10^{8}$ \\
\hline
\end{tabular}

* Bacterial counts expressed as mean \pm SEM colony-forming units of bacteria per gram of cecum.

${ }^{\ddagger} P \leq 0.05$ versus endotoxin, allopurinol plus endotoxin, or tungsten diet plus endotoxin. duced bacterial translocation by allopurinol is a specific response related to the ability of allopurinol to inhibit xanthine oxidase.

Because the effect of endotoxin on the gut also could be mediated by platelet-activating factor (PAF), the ability of a selective competative inhibitor of PAF (SRI 63-441) to reduce endotoxin-mediated bacterial translocation was tested using both $E$. coli 0111 :B4 and $E$. coli 026:B6 endotoxin. At the dose tested, SRI 63-441 did not prevent endotoxin-induced bacterial translocation (Fig. 2). To confirm these results we tested the effect of a second PAF antagonist (BN 52021) on E. coli 0111:B4 endotoxin-induced bacterial translocation. BN 52021 did not appear to alter endotoxin-induced bacterial translocation, since endotoxin promoted bacterial translocation in $60 \%$ (6 of 10) of the mice pretreated with BN 52021. Lastly, we tested the ability of polymyxin-B, an antibiotic with antiendotoxin properties, to prevent endotoxin-mediated bacterial translocation. Polymyxin-B reduced the incidence of bacterial translocation in mice challenged with either $E$. coli 0111:B4 and $E$. coli 026:B6 endotoxin preparations (Table IV). The reduction of bacterial translocation did not appear to be related to the antibacterial effects of polymyxin-B, because gentamicin, an antibiotic with a similar spectrum of antibacterial activity, did not prevent bacterial translocation in mice receiving endotoxin.

$E$. coli was the predominant organism cultured from the MLNs of these mice, although Proteus, Enterococcus, Pseudomonas, and Staphylococcus also translocated to the MLNs.

\section{Discussion}

There is increasing clinical and epidemiologic evidence that gut failure may be associated with loss of barrier function to bacteria and/or endotoxin, as well as malabsorption or ileus (1, 2, 11). Recently, Fry (12) and Garrison (13) incriminated the gut as the focus of invasive sepsis in surgical patients and Stone (14) demonstrated that the gut is a primary reservoir for systemic Candida infections. Although a clinical relationship between gut failure and sepsis has been identified, the conditions leading to gut failure and bacterial translocation have not been fully clarified. Thus, we have used a number of different animal models to determine the conditions that are associated with gut-derived infections. To date, three general mechanisms have been identified that promote bacterial translocation; namely, disruption of the ecology of the indigenous flora of the gut, resulting in intestinal bacterial overgrowth with certain enteric bacilli, impaired host immune defenses, and physical damage of the intestinal mucosa $(3,4,15)$.

Because endotoxin may increase the permeability of the gut (16) and alter host immune defenses (17), is relatively common after thermal $(18,19)$ or mechanical (11) trauma, and is associated with conditions leading to multiple-organ failure $(20,21)$, we previously investigated whether nonlethal doses of endotoxin could promote bacterial translocation from the GI tract (5). These studies documented that endotoxin ( $E$. coli $026: \mathrm{B6}$ ) promotes the translocation of certain indigenous bacteria from the GI tract to the MLN in a dose-dependent fashion. Furthermore, the combination of a nonlethal dose of endotoxin plus a protein-malnourished state or a nonlethal thermal injury results in lethal sepsis $(6,7)$. However, to develop therapeutic strategies to prevent gut-associated bacteria from causing infections, it is necessary to define clearly the 

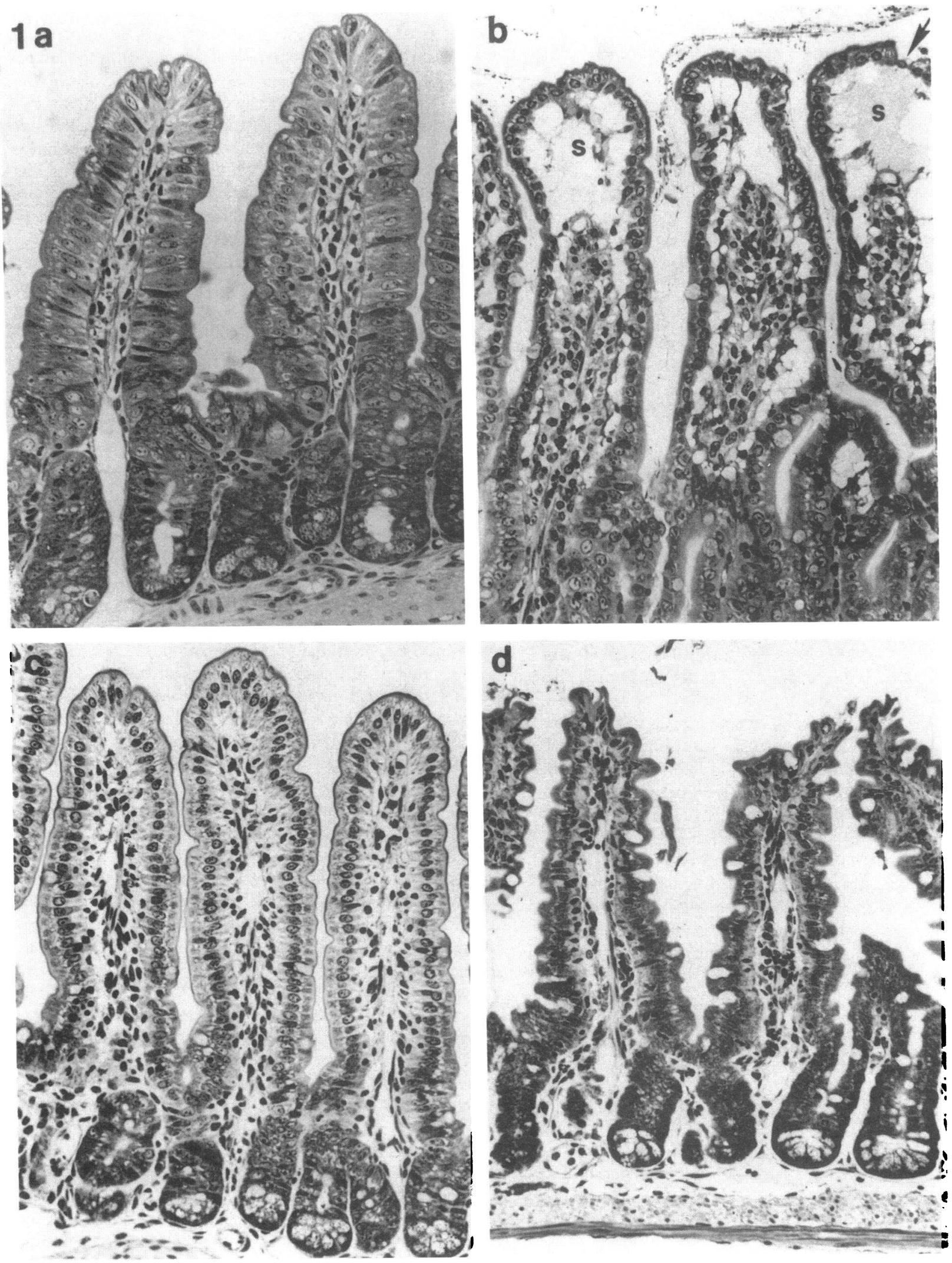

Figure 1. $(a-d)$ Light microscopic evaluation of distal ileum embedded in methylmethacrylate, sectioned at $2 \mu \mathrm{m}$, and stained with toluidine blue. $\times 245$. Control distal ileum $(a)$ exhibits an intact mucosal barrier with normal lamina propria. The presence of endotoxin $(b)$ results in acute mucosal damage. The apical portion of the villous epithelium has detached from the underlying basal lamina resulting in large subepithelial spaces $(s)$ and gross gaps (arrow) in the epithelium are apparent. Animals maintained on a tungsten diet for $14 \mathrm{~d}$ before endotoxin exposure (c) exhibit entirely normal mucosal morphology. Animals given allopurinol to block xanthine oxidase activity $(d)$ exhibit an apparently intact mucosal barrier although the epithelial cells appear abnormally shrunken. 
Table III. Effect of Allopurinol Pretreatment on Bacterial Translocation in Mice Monoassociated with E. coli C25

\begin{tabular}{ccccc}
\hline & \multicolumn{2}{c}{ Translocation to MLN } \\
Group & $n$ & Incidence* $^{*} \quad$ CFU/MLN & CFU/g cecum \\
\hline
\end{tabular}

$\%$

$\begin{array}{lllll}\begin{array}{c}E \text { c coli } \mathrm{C} 25 \\ \text { monoassociated }\end{array} & 8 & 100 & 2.7 \pm 2.1 \times 10^{3} & 3.6 \pm 0.8 \times 10^{10} \\ \begin{array}{c}\text { E. coli } \mathrm{C} 25 \\ \text { monoassociated } \\ \text { plus allopurinol }\end{array} & 8 & 100 & 2.6 \pm 2.5 \times 10^{3} & 2.1 \pm 0.5 \times 10^{10}\end{array}$

* Incidence is expressed as percent of mice with viable $E$. coli $\mathrm{C} 25$ in their MLNs.

‡ Bacterial counts expressed as mean \pm SEM colony-forming units (CFU) E. coli $\mathrm{C} 25$ per gram of MLN.

${ }^{\S}$ Bacterial counts expressed as mean \pm SEM CFU $E$. coli $\mathrm{C} 25$.

mechanisms responsible for gut failure leading to bacterial translocation.

In this study, we investigated whether inhibition of xanthine oxidase by allopurinol or inactivation of xanthine oxidase by a sodium tungstate diet would also prevent endotoxin-induced bacterial translocation. These agents were tested because recent studies have implicated xanthine oxidase-generated oxygen-free radicals as mediators of tissue injury in ischemia-induced intestinal injury (22). Either pretreatment with allopurinol or administration of a tungstate diet reduced the incidence of endotoxin-induced bacterial translocation. These agents appeared to block bacterial translocation by preventing endotoxin-induced mucosal or epithelial damage rather than by altering cecal population levels of the translocating bacteria. In fact, bacterial translocation was reduced in the endotoxin-treated mice fed the tungstate diet even though they exhibited the highest cecal population levels of bacteria.

An inherent assumption in our use of allopurinol and the tungsten-supplemented diet is that these treatment regimens prevent oxyradical formation by the enzyme, xanthine oxidase. Alternate explanations for the beneficial actions of allopurinol have been proposed. They include preservation of the

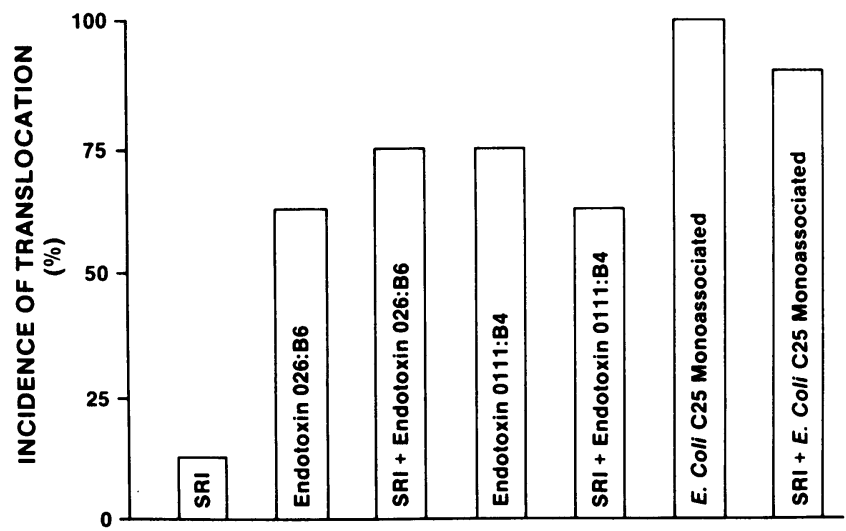

Figure 2. The PAF inhibitor SRI 63-441 did not reduce the incidence of bacterial translocation to the MLN, of mice challenged with $E$. coli 026:B6 or $E$. coli 0111:B4 endotoxin, nor did it prevent bacterial translocation in mice monoassociated with E. coli $\mathrm{C} 25$. nucleotide pool and free radical scavenging, however, the results of several studies in the small bowel argue against a major role for purine salvage or free radical scavenging in the protection afforded by allopurinol (23). Others have also documented that allopurinol can protect cells from endotoxin-mediated injury (24). Relatively little is known about the side effects of a molybdenum deficient, tungsten-supplemented diet. However, a possible limitation of this approach is that other molybdenum-containing, radical-producing, enzymes besides xanthine oxidase (e.g., aldehyde oxidase) are inactivated by tungsten supplementation $(8,23)$.

The specific mechanism(s) involved in endotoxin-induced xanthine oxidase activation or bacterial translocation remain unclear. Inasmuch as endotoxin can alter intestinal blood flow (25), it is possible that the intestinal ischemia induced by endotoxin initiates the activation of xanthine oxidase $(8,23)$. Another possibility is that endotoxin indirectly induces activation of xanthine oxidase through the liberation of secondary mediators. The latter possibility is supported by observations that endotoxin administration elevates IFN levels, and that IFN inducers, such as poly-I-C, increase tissue xanthine oxidase activity (26). Recently, Mathan et al. (27) documented that subcutaneous injections of endotoxin will cause endothelial cell damage in the venules and capillaries of the lamina propria of mice enterally colonized with Salmonella. Thus, it is possible that the mucosal and epithelial damage seen in our endotoxin-challenged mice may also be related to a microvascular injury. Nonetheless, the potential causal association between increased xanthine oxidase activity and mucosal damage documented in this study, is further strengthened by our recent findings that hemorrhagic shock-induced mucosal injury and bacterial translocation are both reduced by xanthine oxidase inhibition or inactivation (28).

Although activation of xanthine oxidase appears to be of primary importance in the pathogenesis of bacterial translocation in endotoxin-treated mice, preventing xanthine oxidase activation did not prevent bacterial translocation in mice monassociated with $E$. coli $\mathrm{C} 25$. These findings indicate that a single mechanism is not responsible for promoting bacterial translocation in all situations. It is likely that several distinct mechanisms are responsible for promoting bacterial translocation, depending on the exact clinical or experimental situation.

The synthesis and release of various proinflammatory mediators have been documented after endotoxemia, and recently it has become clear that many of the toxic effects of endotoxin are dependent on the release of these endogenous factors by the host (25). Therefore, we investigated whether endotoxin-induced bacterial translocation could be mediated by PAF. There are many reasons to suspect that endotoxin-induced bacterial translocation might be mediated by PAF. PAF is produced by many cells, such as macrophages, neutrophils, platelets, and endothelial cells. The biologic effects of PAF include increased vascular permeability, hypotension, and death $(25,29)$. Furthermore, endotoxin-induced hypotension is associated temporally with detectable levels of plasma PAF, and PAF antagonists reverse endotoxin shock $(30,31)$. Lastly, Sun et al. (32) recently have implicated PAF as the mediator of bowel necrosis induced by endotoxin or tumor necrosis factor. Although the synthetic PAF receptor antagonist, SRI 63-441, inhibits the major physiologic responses to PAF in several species, including the rat (10), it did not prevent endotoxin-in- 
Table IV. Effect of Endotoxin, Endotoxin plus Polymyxin-B, or Endotoxin plus Gentamicin on Bacterial Translocation to MLN

\begin{tabular}{llcccc}
\hline \multicolumn{1}{c}{ Group } & & & \multicolumn{2}{c}{ Cecal bacterial levels* } \\
\cline { 5 - 6 } & $n$ & Incidence of translocation & Gram-negative enterics & Total aerobic \\
\hline E. coli 026:B6 endotoxin & & $\%$ & & ND & ND \\
Polymyxin-B plus endotoxin (026:B6) & 24 & 71 & ND & ND \\
E. coli 0111:B4 endotoxin & 16 & $29^{\ddagger}$ & 75 & $7.2 \pm 1.7 \times 10^{8}$ & $11.9 \pm 2.3 \times 10^{8}$ \\
Polymyxin-B plus endotoxin (0111:B4) & 16 & $13^{\S}$ & $8.9 \pm 1.7 \times 10^{8}$ & $14.4 \pm 2.2 \times 10^{8}$ \\
Gentamicin plus endotoxin (0111:B4) & 16 & 69 & $11 \pm 1.9 \times 10^{8}$ & $17.9 \pm 3.4 \times 10^{8}$ \\
\end{tabular}

* Bacterial counts expressed as mean \pm SEM colony-forming units per gram of cecum. ${ }^{\ddagger} P \leq 0.01$ versus $E$. coli $026: B 6$ endotoxin. ${ }^{\S} P \leq 0.01$ versus $E$. coli 0111:B4 endotoxin or gentamicin plus $E$. coli 0111:B4 endotoxin.

duced bacterial translocation in our mouse model. To confirm these findings with SRI 63-441, a second PAF antagonist BN 52021 was also tested. BN 52021 was also ineffective in reducing endotoxin-induced bacterial translocation. These results suggest that the effect of endotoxin (at the doses tested) on the antibacterial barrier function of the gut is not primarily mediated by PAF.

Experiments using polymyxin-B were carried out to determine whether endotoxin-induced bacterial translocation could be prevented by a substance that inactivates endotoxin. The rationale for using polymyxin-B to antagonize the effects of endotoxin is based on the fact that the polymyxin-B group of cationic antibiotics interferes with the biologic action of endotoxin by stoichiometrically binding to the endotoxin molecule (33). However, polymyxin-B exhibits antibiotic as well as antiendotoxin properties. Consequently, gentamicin, an antibiotic with a similar antibacterial spectrum but without antiendotoxic properties, also was tested. Polymyxin-B, but not gentamicin, reduced the incidence of endotoxin-induced bacterial translocation. These results are consistent with the work of others who have demonstrated that polymyxin-B increases survival in animals challenged with carbon tetrachloride (34) or endotoxin (35).

Endotoxin has a wide range of biologic actions, including the ability to modulate the immune system, increase vascular permeability, impair cellular metabolism and oxygen utilization, initiate disseminated intravascular coagulation, and produce profound hemodynamic changes resulting in hypotension and death. On the basis of our studies, it is now clear that nonlethal doses of endotoxin also will promote bacterial translocation from the gut of healthy mice with an intact indigenous GI microflora. It appears that endotoxemia can become self-sustaining in circumstances in which systemic endotoxin induces the absorption of intestinal endotoxin. These results may be of clinical significance, as the GI tract has been increasingly implicated as the source of bacterial infections in stressed $(1,2)$, traumatized $(11,12,13,21)$, or immunocompromised $(14,36,37)$ patients. Selective antibiotic decontamination of the GI tract reduces the incidence of infectious complications and improves survival in some series of patients with leukemia, lymphoma, or granulocytopenia $(38,39)$.

The clinical finding that antimicrobial control of the gut flora is not sufficient to prevent infections with enteric bacteria in all patient groups is not surprising. Bacterial translocation may be induced by several different mechanisms, only one of which appears to be related to the disruption of the ecology of the indigenous gut microflora. The results of this study suggest that other therapeutic modalities in addition to selective antibiotic decontamination of the gut may be needed to prevent systemic infections from translocating bacteria, especially in patients who are endotoxemic. The development of clinical strategies, however, must await further experimental work to determine the exact mechanism(s) whereby bacteria translocate from the gut to systemic organs and cause systemic infections.

\section{Acknowledgments}

This work was supported by National Institutes of Health grant GM-36376.

\section{References}

1. Border, J. R., J. Hassett, J. LaDuca, R. Seibel, S. Steinberg, B. Mills, P. Losi, and D. Border. 1987. Gut origin septic states in blunt multiple trauma (ISS-40) in the ICU. Ann. Surg. 206:427-446.

2. Carrico, D. J., J. L. Meakins, J. C. Marshall, D. Fry, and B. V. Maier. 1986. Multiple organ failure syndrome. Arch. Surg. 121:196308.

3. Berg, R. D., and A. W. Garlington. 1979. Translocation of certain indigenous bacteria from the gastrointestinal tract to the mesenteric lymph nodes and other organs in a gnotobiotic mouse model. Infect. Immun. 23:403-411.

4. Deitch, E. A., K. Maejima, and R. Berg. 1985. Effect of oral antibiotics and bacterial overgrowth on the translocation of the GI tract microflora in burned rats. J. Trauma. 25:385-392.

5. Deitch, E. A., R. Berg, and R. Specian. 1987. Endotoxin promotes the translocation of bacteria from the gut. Arch. Surg. 122:185190.

6. Deitch, E. A., and R. D. Berg. 1987. Endotoxin but not malnutrition promotes bacterial translocation of the gut flora in burned mice. J. Trauma. 27:161-166.

7. Deitch, E. A., J. Winterton, M. Li, and R. Berg. 1987. The gut as a portal of entry for bacteremia: Role of protein malnutrition. Ann. Surg. 205:681-692.

8. Smith, S. M., M. B. Grisham, E. A. Manci, D. N. Granger, and P. R. Kvietys. 1987. Gastric mucosal injury in the rat: role of iron and xanthine oxidase. Gastroenterology. 92:950-956.

9. Waud, W. R., and K. V. Rajagopalan. 1976. Purification and properties of the $\mathrm{NAD}^{+}$dependent (type D) and $\mathrm{O}_{2}$-dependent (type O) form of rat liver xanthine dehydrogenase. Arch. Biochem. Biophys. 172:354-364.

10. Handley, D. A., J. C. Tomesch, and R. N. Saunders. 1986. Inhibition of PAF-induced systemic responses in rat, guinea pig, dog, 
and primate by the receptor antagonist SRI 63-441. Thromb. Haemostasis 56:40-44.

11. Woodruff, P. W., D. I. O'Carroll, S. Koizumi, and J. Fine. 1973. Role of the intestinal flora in major trauma. J. Infect. Dis. 128:S290-S294.

12. Fry, D. E., T. W. Klamer, R. N. Garrison, and H. C. Polk, Jr. 1981. Atypical clostridial bacteremia. Surg. Gynecol. Obstet. 153:2830.

13. Garrison, R. N., D. E. Fry, S. Berberich, and H. C. Polk, Jr. 1982. Enterococcal bacteremia: clinical implications and determinants of death. Ann. Surg. 196:43-47.

14. Stone, H. H., L. D. Kolb, C. A. Currie, C. E. Geheber, and J. Z. Cuzzell. 1974. Candida sepsis: pathogenesis and principles of treatment. Ann. Surg. 179:697-711.

15. Deitch, E. A. 1988. The immunocompromised host. Surg. Clin. North Am. 68:181-190.

16. Walker, R. I. 1978. The contribution of endotoxin to mortality in hosts with compromised resistance: a review. Exp. Hematol. 6:172184.

17. Morrison, D. C., and J. L. Ryan. 1979. Bacterial endotoxins and host immune responses. Adv. Immunol. 28:293-450.

18. Jones, R. J., and E. A. Roe. 1979. Measurement of endotoxins with the Limulus test in burned patients. J. Hyg. 83:151-156.

19. McManus, A. T., R. B. Lindberg, B. A. Pruitt, and A. D. Mason. 1977. Biomedical Applications of the Horseshoe Crab. Alan R. Liss, Inc., New York. 275-278.

20. Howard, R. T. 1982. Microbes and their pathogenicity. In Surgical Infectious Disease. R. L. Simmons and R. J. Howard, editors. Appleton-Century-Crofts, Norwalk, CT. 11-28.

21. Caridis, D. T., R. B. Reinhold, P. W. Woodruff, and J. Fine. 1972. Endotoxemia in man. Lancet. ii:1381-1386.

22. Parks, D. A., G. B. Bulkley, D. N. Granger, S. R. Hamilton, and J. M. McCord. 1982. Ischemic injury in the cat small intestine: role of superoxide radicals. Gastroenterology. 82:9-15.

23. Granger, D. N. 1988. Role of xanthine oxidase and granulocytes in ischemia-reperfusion injury. Am. J. Physiol. 244 (Heart Circ. Physiol.) 24:1269-1275

24. Brigham, K. L., B. Meyrick, L. C. Berry, and J. E. Repine. 1987. Antioxidants protect cultured bovine lung endothelial cells from injury by endotoxin. J. Appl. Physiol. 63:840-850.

25. Morrison, D. C., and J. L. Ryan. 1987. Endotoxins and disease mechanisms. Annu. Rev. Med. 38:417-432.

26. Ghezzi, P., M. Bianchi, A. Mantovani, F. Speafico, and M. Salcona. 1984. Enhanced xanthine oxidase activity in mice treated with interferon and interferon inducers. Biochem. Biophys. Res. Commun. 119:144-149.
27. Mathan, I. V., G. R. Penny, M. M. Mathan, and D. Rowley. 1988. Bacterial lipopolysaccharide-induced intestinal microvascular lesions leading to acute diarrhea. J. Clin. Invest. 82:1714-1721.

28. Deitch, E. A., W. Bridges, J. Baker, W. Jing, L. Ma, M. Grisham, N. Granger, and R. Berg. 1988. Hemorrhagic shock-induced bacterial translocation is reduced by xanthine oxidase inhibition or inactivation. Surgery (St. Louis). 104:191-198.

29. Braquet, P., L. Touqui, T. Y. Shen, and B. B. Vargaftig. 1987. Perspectives in platelet-activating factor research. Pharmacol. Rev. 39:97-145.

30. Chang, S. W., C. O. Feddersen, P. M. Henson, and N. F. Voelkel. 1987. Platelet-activating factor mediates hemodynamic changes and lung injury in endotoxin-treated rats. J. Clin. Invest. 79:1498-1509.

31. Doebber, T. W., M. S. Wu, J. C. Robbins, B. M. Choy, M. N. Chen, and T. Y. Shens. 1985. Platelet-activating factor involvement in endotoxin-induced hypertension in rats: studies with PAF-receptor antagonist kadsurenone. Biochem. Biophys. Res. Commun. 127:799808.

32. Sun, X. M., and W. Hsueh. 1988. Bowel necrosis induced by tumor necrosis factor in rats is mediated by platelet-activating factor. $J$. Clin. Invest. 81:1328-1331.

33. Jacobs, D. M., and D. C. Morrison. 1977. Inhibition of the mitogenic response to LPS in mouse spleen cells by polymyxin-B. $J$. Immunol. 118:21-27.

34. Nolan, J. P., and A. I. Leibowitz. 1978. Endotoxin and the liver. III. Modification of acute carbon tetrachloride injury by polymyxinB-an antiendotoxin. Gastroenterology. 75:445-449.

35. Rifkin, D. 1967. Prevention by polymxyin-B of endotoxin lethality in mice. J. Bacteriol. 92:1463-1464.

36. Wells, C. L., R. P. Podzorski, P. K. Peterson, N. K. Ramsay, R. L. Simmons, and F. S. Rhame. 1984. Incidence of trimethoprimsulfamethoxazole-resistant Enterobacteriaceae among transplant recipients. J. Infect. Dis. 150:699-706.

37. Bodey, G. P. 1981. Antibiotic prophylaxis in cancer patients: regimens of oral, nonabsorbable antibiotics for prevention of infection during induction of remission. Rev. Infect. Dis. 3(Suppl.):S259-S268.

38. Gurwith, M. J., J. L. Brunton, B. A. Lank, G. K. M. Harding, and A. R. Ronald. 1979. A prospective controlled investigation of prophylactic trimethoprim/sulfamethoxazole in hospitalized granulocytopenic patients. Am. J. Med. 66:248-256.

39. DeVries-Hospers, H. G., D. T. Sleijfer, N. H. Mulder, D. van der Waaij, H. O. Nieweg, and H. K. F. van Saene. 1981. Bacteriological aspects of selective decontamination of the digestive tract as a method of infection prevention in granulocytopenic patients. Antimicrob. Agents Chemother. 19:813-820. 